\title{
Worries with the Web: A Look at Student Use of Web Resources
}

\section{Deborah J. Grimes and Carl H. Boening}

\begin{abstract}
The purpose of this research project was to determine whether students are using unauthenticated resources, whether they are evaluating their resources, and whether there is a gap between the quality of resources expected by instructors and the quality of resources used by students. Using case study methodology, the authors interviewed instructors and students and analyzed Web resources cited in research papers in two English composition classes. The findings show that students are using unevaluated resources and that there is a gap between what instructors expect students to use and what students actually use. Ways to alleviate "worries with the Web" are discussed.
\end{abstract}

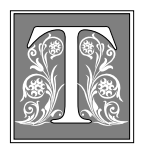

he authors are concerned that, despite the best efforts of academic librarians to provide high-quality print and electronic resources, college students are using unevaluated or inappropriate Web resources to support their writing assignments. Evidence that this concern is widespread is apparent in the development of hundreds of online guides evaluating Web resources and in anecdotal literature lamenting how easily students are seduced by the convenience and speed with which they can locate what they consider to be good information on the Web. Experts such as Evan Ira Farber have pointed out that today's students, like those of a generation ago, still cannot separate the good from the bad when locating information sources. ${ }^{1}$

The authors do not mean to imply that all Web-based resources are of poor quality; on the contrary, there are numerous examples of high-quality resources on the
Web and a growing body of review tools, in both print and online formats, to help librarians and others identify worthwhile sites. However, students find Web resources easily accessible and convenient without needing the intervention or assistance of a librarian, so there are greater opportunities for them to select sources of dubious value and quality. Although the authors celebrate the Web as an outstanding vehicle for information, they also are concerned about student use of Web resources-and they are not alone in their concern. In an article entitled "How the Web Destroys Student Research Papers," Professor David Rothenberg complained that he has "noticed a disturbing decline in both the quality of the writing and the originality of thoughts expressed." He suggested that this decline is caused by the use of Web resources, with out-of-date references, unattributed quotes, and "what passes for information" on the Web. ${ }^{2}$

Deborah J. Grimes is the Director of Library Services at Shelton State Community College; e-mail: dgrimes@shelton.cc.al.us. Carl H. Boening is the Library Systems Officer at Shelton State Community College; e-mail: cboening@shelton.cc.al.us. 
Moreover, a gap seems to exist between what many instructors expect of resources traditionally provided by an academic library and what the students actually use from the Web. There are at least two reasons why such a gap should exist. First, instructors are accustomed to relying on librarians to ensure the quality of resources available for student use. After all, librarians have worked with written selection criteria for decades, involving faculty experts in the development of subject collections and applying years of collection development experience to selecting materials. Indeed, they are using the same infrastructure to develop online guides to Web resources. However, students now have more and more opportunities to bypass the selection and quality control traditionally provided by librarians and are relying, instead, on search engines that rank by relevancy, rather than quality, to locate online sources that seem to meet their needs, without ever considering the quality and authority of those sources. Kari Boyd McBride and Ruth Dickstein have pointed out that the Web has no gatekeeper and that there is "a major difference between the types of information found on the Web and the type one finds in a library." ${ }^{13} \mathrm{Com}-$ pounding the situation is the fact that students are searching the Web not only at home, but also in the libraries, where they, like their instructors, have come to expect others to maintain quality. In fact, librarians may have created this problem by doing their jobs so well for so long. By moderating their collections, they have removed the need for instructors and students to evaluate resources.

With little or no evidence, Web users often assume that Web resources are current and up-to-date.

A second reason why a gap between faculty expectations and student use of Web resources may exist has been proposed by Gloria J. Leckie. The so-called expert researcher model used by academic faculty presupposes that students have the same high level of skills to judge and evaluate sources of information. ${ }^{4}$ In other words, faculty members expect students to conduct research in the same ways they do and may not even be aware that they are operating in the "expert researcher" mode of thinking.

\section{Literature Review}

The authors examined the literature in the fields of higher education and library and information science to gather some perspective on student use and faculty expectations of Web resources. A basic overview of the literature was offered by Susan E. Hahn, who reported that articles began to emerge in 1996 about teaching students to evaluate Internet sources. ${ }^{5}$ Julia K. Nims and Linda Rich used the Search Voyager feature of Magellan, an online guide to the Web, to examine student search techniques and found that problems caused by poor search strategies are "magnified when they are conducted on the Web." ${ }^{\prime 6}$ Ann Scholz-Crane examined the evaluation practices of two groups of college composition students. One group used a checklist provided by the instructor, and the other group developed its own criteria to evaluate two Web documents. Comparing criteria from both groups to standard evaluation criteria, she found that a checklist alone was insufficient to help students evaluate Web sites and, further, that students needed help in identifying components or elements of Web documents. ${ }^{7}$

In an effort to increase effective use of the Internet for research, Anne F. Pierce used pre- and posttest scores to compare the performances of high school students. She found that, despite their high opinions of their own abilities, students were quite unskilled in research techniques that effectively used Internet resources. She further found that, for a variety of reasons, high school teachers in the study were unprepared to help students learn how to evaluate Internet sources and to develop search strategies. ${ }^{8}$

Mary Ann Gilette and Carol Videon used a case study to examine the sources cited by forty-seven students in a com- 


\section{FIGURE 1 \\ Interview Questions for Instructors}

1. May we have a copy of your syllabus and/or written instructions regarding the research paper assignment?

2. What instructions did you give your students in class regarding sources for their research papers? Be specific, as if I were your student.

3. Did you specifically mention Internet or Web sources? Did you give them any criteria to use to help them select sources on the Internet?

4. What kinds of sources did you expect your students to use? Why?

5. Did you expect students to go directly to the Internet or Web to find information? From home? From the library?

6. What quality of information did you expect them to find on the Internet or Web? Compared to traditional print resources from the library (books and journals)?

7. What qualities or characteristics do you think make an Internet site or a Web site a good source for research papers? Be specific. Prompt, if necessary: the same as for books or journals?

8. Do you use the Internet or Web? For what? For locating information similar to that needed by your students? If so, how do you decided what's good and what's not?

9. Did your students meet your expectations regarding the sources they used (print and online)? Why or why don't you think they did?

10. Do you think Internet or Web sources are different from books and journals? If so, in what ways? How are they alike?

munity college writing class. They found that, regardless of a wide range in quality, 50 percent of the students in their study cited other student papers found online. Citations to Web documents were often muddy, with a high degree of faulty links and errors; and students often cited several sections or chapters of one Web site as multiple sources. ${ }^{9}$

\section{Purpose of the Study}

To get a better idea of what students are doing and what faculty members expect of them, the authors conducted a study to determine three things:

1. Are students evaluating Web resources?

2. Are they using unauthenticated Web resources?

3. Is there a gap between what instructors expect of their students and what students are actually doing with Web resources?

\section{Methodology}

Case studies were conducted of community college instructors and their freshman writing classes, using two classes of English Composition II (ENG 102), which requires research papers, including documentation (i.e., references and a bibliography). The research paper is the first major writing activity that requires students to identify, evaluate, and use outside references to support a point of view or provide a detailed description or biography.

One class of twenty-five students was assigned a biographical research paper. The only instructions related to Web sources were directed toward proper citation formats. Six students in this class used electronic sources of information, with a total of seventeen citations to Web documents. The second class, also of twenty-five students, was assigned a research paper on a current controversy (e.g., gun control, abortion, and so on). Five students used electronic sources, with a total of fifteen citations to Web documents.

Three methods were used to obtain as many data as possible: (1) instructor interviews to learn more about the instructions given to students regarding required 
references, about directions given regarding use of the Internet or Web resources, about the quality of sources instructors expected students to use, and about how the instructors judged the quality of Web resources (see figure 1); (2) student interviews to determine the students' understanding of the quality of resources they chose (see figure 2); and (3) an analysis of the bibliography of each research paper to identify the types and quality of sources used. The authors attempted to access each URL (universal resource locator) cited by the students and to assess its quality according to specific criteria.

\section{Evaluating the Quality of Web Resources}

Drawing from numerous online guides, a checklist was developed of criteria for Web resources used in the writing assignment. The authors found a great deal of similarity among the guides, highly reflective of traditional selection criteria used in evaluating print resources in academic libraries. ${ }^{10}$ Ten criteria were identified for use in evaluating Web resources: authorship; currency; recommendations; perspective; audience; style and tone; quality of content; organization of information; publisher, source, and host; and stability of information. These criteria are explained in more detail in table 1. Although each source was not expected to meet all ten criteria, each was expected to meet at least some of the criteria in order to be considered suitable for undergraduate college writing assignments.

These criteria take on more importance for Web resources because of the differences between traditional print resources and Web resources. For example, the scholarly communication system-with its checks and balances of publishers, editors, peer review, and librarians-manages and controls access to traditional print resources. That is, the scholarly communication system generally prevents informal, poorly designed, and difficultto-use sources from ever getting into the hands of users. Further, it ensures that authors of print resources have been through some form of review and evaluation. However, there is no systematic monitoring of authority on the Web. Likewise, perspective (biases, hidden agen-

\section{FIGURE 2}

\section{Interview Questions for Students}

1. What instructions did your teacher give you about using sources for your research paper?

2. What specific kinds of sources were mentioned? Were Internet or Web sources mentioned?

3. Was any direction provided by your teacher regarding how you would choose good sources on the Internet or Web?

4. What made you choose the sources you did (print and Internet/Web)? i.e., how did you know they were appropriate or good for your assignment?

5. Have you used the Internet or Web for these kinds of assignments before? For other things? Where? (Home, work, library, classroom)

6. Did you consciously think about the quality of the Internet or Web sites or sources you chose? If so, what kinds of things did you think of (e.g., source, author, date, etc.)?

7. Do you think you met your teacher's expectations for finding appropriate sources for your paper? Why or why not?

8. How easy was it to locate information on your topic in library books and ournals?

9. How easy was it on the Internet?

10. Which sources did you find most useful? Books? Periodicals? Internet? Why?

11. Did you ask for help in the library to locate books? Periodicals? Internet sources? 
TABLE 1

Web Evaluation Criteria

\begin{tabular}{ll} 
Criterion Description \\
\hline
\end{tabular}

1. Authorship

2. Currency

3. Recommendations

4. Perspective

5. Audience

6. Style and tone

7. Quality of content

8. Organization of information

9. Publisher, source, host

10. Stability of information
Authors should be identified, with appropriate credentials evident.

Dates should provided for each source, which are current or timely enough to be appropriate to the research paper topic. Web resources, both individual pages and databases, should be updated regularly.

It should be evident that Web resources have been through some review process or recommended by reliable outside sources. Web resources include online databases, which moderate information like their print counterparts, as well as personal pages.

Biases and affiliations should be evident on Web resources, including commercial affiliations.

Intended audiences (laypersons, fans, professionals, specialists, educators, etc.) should be evident.

Style and tone should be appropriate to the topic. Web resources should meet the same criteria for grammar, spelling, and documentation that print resources meet. Sites should be user-friendly and in good taste to be appropriate for research papers.

Content should be timely, documented, verifiable, and accurate. Limitations should be pointed out. Information should be detailed enough to be appropriate to the research paper topic. Information should be relevant to the topic.

Resources should be well organized, easy to follow and use, with reliable links.

Publishers, hosts, and sources provide some of the authority associated with any Web resource. They should be evident to the user and appropriate to the topic.

Web sites and the information on them should be relatively stable over time, as should basic information. Changes in information (or updates) should be indicated. 
das, commercial promotions, and so on) is not monitored on the Web in the same way that it is in the scholarly communication system. With little or no evidence, Web users often assume that Web resources are current and up-to-date. Where a reader may easily note the copyright date of a book or the publication date of a periodical article, he or she may assume that a Web resource is up-to-date simply because it is online or on the Web. The reader expects to find current information on the Web but may have to look harder, in some cases, to verify currency of information for Web resources, sometimes going through several online pages to find information about the site or the document. Because there is no standard format for Web pages or Web documents, important bibliographic information, such as date, is not always easy to locate, if it is provided at all.

Organization of information is different and more important to evaluate in Web resources than in traditional print resources for two reasons. First, the scholarly communication system ensures that the author is presenting information in an orderly and logical manner appropriate to the topic. Second, printed information follows established linear formats to ensure good organization. In contrast, Web resources, with hypertext links, need not be organized linearly, although they must be easy to follow and must facilitate movement from page to page and link to link.

Finally, the stability of information is not an issue with traditional print resources. Once in print, information remains fixed in one or more formats. A new edition or a revision may be published, but these are different physical items that may be placed side by side with the original text. A Web resource may be edited or revised very easily; many Web documents, in fact, are intentionally designed to change as necessary. Once changed, however, the original electronic source disappears. The protean qualities of the Web and Web documents create problems with fragility of information that are not at issue in traditional print resources.

\section{Results}

As with any research project, the authors must acknowledge the limitations of the present study. The numbers of students, instructors, and analyses of Web resources in this project were quite small, which means that results cannot be generalized without caution. Furthermore, hindsight from interviewees is less reliable than direct observation. However, consistency was found among responses to interview questions and in the analyses of sources used by students. Studies reported in the literature are comparable in terms of number of subjects used, methodology used, and findings.

\section{Interviews with Faculty}

The instructor for the first class gave no specific instructions regarding the use of electronic or Web resources, except for documentation formats. She expressed reservations about even allowing her students to use the Web for this assignment. In fact, she said, "I feel very naive about the Internet. I don't use it and am not familiar with what is available." Prior to this assignment, she never expected students to conduct research from their homes and expected Web documents to be "good." She was surprised to learn, primarily from students, that many Web documents do not indicate authors and other bibliographic information used in traditional documentation.

She then suggested the following as characteristics of a "good" Web source for the biography assignment: reliable author, currency, and reputable sources. She particularly instructed her students to "separate gossip and rumor" from authoritative sources but was unaware that they would find such things as other student papers, personal Web pages devoted to celebrities and sports figures, and other unsubstantiated documents. The instructor did not expect Internet sources to be different in quality from the books, journals, and reference materials used by her 
students in the past (located in libraries). Moreover, she was unaware that the campus library offers an online database specifically on biographical information.

The instructor for the second class, like her counterpart, stated clearly that she was not particularly skilled in using the Internet and had reservations about making it a part of the research paper assignment. Relying heavily on the textbook, she did make an effort to acquaint her students with ways to conduct Internet research. She mentioned specific search engines and emphasized that students should use the databases available in the campus library. Further, she expected her students to find good-quality Web information without personally having used the Web to do research herself. She emphasized the need to locate Web resources with authors and other information necessary for documentation of their papers, but she did not give specific instructions about identifying authors and assessing their credentials. Finally, she was disappointed that her students did not find more reliable and better-quality information on the Internet than they actually did.

The second instructor stated that a high-quality Web source should have an author with credentials appropriate to the site or the topic and that the site should not be clearly biased in any way. When asked whether she felt that her students had met her expectations regarding Web resources, her answer was an emphatic no. She felt that her students had ignored her advice and the instructions in the textbook and had relied too heavily on search engines to locate information. This was the first time she had allowed students to use Web resources and considered it, overall, to be a negative experience. She was left with the feeling that the Web was not a good source of information and planned to alter procedures for her next research paper assignment.

\section{Interviews with Students}

All of the students who cited Web sources agreed to participate in the interviews. The students in the first class were well aware of the directions provided by the instructor and confirmed that she had given no specific directions regarding Internet sources (except for documentation formats). All of these students used general search engines (e.g., Yahoo!, InfoSeek, Lycos, Excite) to locate information on their topics (citing the search engine as the reason they chose the sources). Although a biographical database is prominent on the library's home page and easily accessible by icon, none of the students realized that it was available in the campus library.

Students in the second class, with a research assignment on current controversies, had varied responses regarding the instructor's directions for Web research. All agreed that she had given some pointers about resources, but not all of them agreed that she had been specific regarding Web resources. Several indicated that the instructor had mentioned search engines (e.g., Lycos, Yahoo!, MSN), and one commented that the instructor had said, "You're on your own," regarding the Internet. Others said that the instructor had told them they should chose "reliable" Web resources, without being specific about what that meant.

Several of the students in both classes asked for assistance in locating books and periodicals on their topics, but none of them asked for assistance in using the library's electronic resources. Most of the students in the second class, with assignments on controversies, stated that they were unable to find current information on their topics in books or periodicals. Of course, the campus library is adequately staffed during day and evening hours with professional librarians (to provide assistance in locating information) and has a wealth of information on current topics, including several online databases and Web resources that students would find relevant to their assignments. However, students went directly to the Internet without looking at the library's offerings.

Most of the students in both classes had used the Internet for research assignments in other classes prior to the assign- 
ment in ENG 102 (e.g., economics, Western civilization, stress management) or for recreational purposes (e.g., electronic mail and chat rooms). All the students thought that locating information on the Internet was "very easy," despite the fact that the sources they found were not always of the quality one might expect for college research papers. They all preferred Internet sources to traditional print sources because of the ease in locating and printing out the results and because of the perceived abundance of information compared to books and periodicals.

Answers to questions of evaluation of sources varied. Several students in the first class stated that they had attempted to locate authors for each Web source but were often unsuccessful. They eliminated sources identified through the search engine only when there was "not enough information or it said the same thing." One student seeking information on a current controversy looked for Web resources published by colleges or universities, whereas another looked for "associations" for her sources. One student specifically mentioned that she had used date as a criterion for choosing a resource, due to assignment guidelines. However, most students simply found matches to their queries on various search engines and took them to be appropriate sources.

Students sometimes equated "how the page looked" with credibility but generally did not consider the design of the site to be an important factor. They formed their own opinions on credibility of the Web sources and did not look for signals from the documents themselves. Most students considered author to be the most important feature of a high-quality Web site, giving no thought to the qualifications of any particular Web author. Most students in both classes thought that they had met their instructor's expectations for finding appropriate sources.

\section{Analysis of Works Cited}

Authorship: Authorship was considered important so that the proper citation format could be used (as required by the in- structor). In other words, any author was acceptable, regardless of credentials. In the second class, most of the students selected sources that clearly identified authors, but less than half of those sources provided credentials for authors. Of those, only a handful of the credentials cited were appropriate to the subject matter.

Currency: Students in both classes were required to use the Modern Language Association (MLA) format for documentation. The MLA format cites the date the student used the electronic source rather than the publication date of the information. Virtually all of the sources cited by students in the first class included a date that was only days prior to the date the paper was due. Therefore, the instructor had no way of knowing whether the source was current without examining it online. Upon online examination, the authors found that less than one-half of the cited sources were in fact timely, with most sources including no date at all. Very few of the Web pages selected by students provided information as to when they were updated, and still fewer were updated with any regularity.

Recommendations: None of the Web resources selected by students in the first class were from sites with recommendations, commendations, or awards. None of the students used Web guides that might lead them to or suggest Web reviews. And less than one-half of the Web resources used by students in the second class had verifiable reviews or recommendations. Only one Web source in either class was from a database that selectively posts articles or papers (i.e., Scientific American).

Perspective: Very few of the sites selected by students overtly suggested a bias or skewed perspective. Several selections were press releases or information from professional associations (such as sports organizations). Half of the Web resources used by students in the second class, assigned to write about controversial subjects, by their nature represented biased viewpoints (although only one 
Web source might be considered "extreme"). The majority of sites used by students in the second class were affiliated with a particular group or organization, although most did a reasonable job of presenting both sides of the issue.

Audience: Several sources were directed toward particular audiences, but the students were unaware that sources might be directed toward specific audiences for specific reasons. The students in the first class selected no scholarly Web sources and expressed no concern about the intended audiences of their Web sources. Half of the Web sources used by students in the second class were clearly aimed at presenting information to a particular audience (e.g., www.euthanasia.com), although all presented information in a format easily understood by laypersons.

Style and Tone: Likewise, students did not consider the style and tone of Web resources to be significant. All of the Web resources used in the second class presented information in a formal manner, with appropriate grammar, spelling, and style. Page designs varied greatly from source to source, but most were appropriate to the subject matter and were clearly laid out and easy to read. Although not all of the Web pages used in the second class contained unbiased materials, all of the presentations were done in a scholarly manner, with most including formal references and links to other Web sites on the subject matter.

Quality of Content: Very few of the Web sources used in the first class included any markers of the quality of content. In fact, there was so little documentation of information on the sites that quality could not be assessed, although the students were quite satisfied with their own judgments of quality. The large majority of Web sites used by students in the second class contained timely material, although several contained information that was of unidentifiable age. In most cases, the scope and limitations of the Web information used in the second class were clearly delineated, but students may not have the expertise to identify these characteristics.
Organization of Information: Web resources used in both classes presented a mixed bag, but most were well organized with links still active at the time the authors analyzed them. However, some were very poorly organized and difficult to track back to the original or home page.

Publisher, Source, Host: Web sources included official Web sites for professional athletic associations, speakers' bureaus, national organizations, press sites, personal home pages, fans' pages, and, in one case, a junior high school class project. During the interviews, students were asked if it concerned them that at least one source selected by a fellow student was a personal home page of a sixteenyear-old fan. No one expressed any concern, asserting that such a site was suitable for college research paper assignments. In all cases in the second class, the affiliations of the source of the pages were evident. Most were official Web sites of organizations or institutions, with only a few being personal sites. In each case where the source of the site was evident, the host clearly provided authority for the site.

Stability of Information: Approximately 30 percent of the Web sites listed in all student papers were unavailable for review, due to either student misreporting of the URL or inactive links (despite the fact that all sites were verified within three weeks of student use). Most of the remaining sites seem likely to remain active for the foreseeable future.

\section{Conclusions}

Are students evaluating Web resources? The study found that students are evaluating Web resources only superficially, if at all. They went directly to Web resources without seeking help from librarians, even when in the campus library. Their instructors provided little guidance to help them select sources, and, like the students in Pierce's study, all were confident in their own assessments of the quality and suitability of the Web sources they found. Unfortunately, the students in the study 
seemed ill equipped and perhaps unwilling to make the effort to evaluate Web resources. Moreover, they had not been taught in class (or did not learn) what was and was not a good Web resource.

Are students using unauthenticated Web resources? The study found that students are indeed using unauthenticated Web resources. As discussed in more detail above, students used everything from junior high school Web sites to publicity sites for information. None of the them took advantage of the availability of databases or Web guides provided by the library.

Is there a gap between what instructors expect of their students and what students are actually doing with Web resources? The study revealed that there is indeed a gap between what instructors expect of their students and what students are actually doing with Web resources. The gap may be in part due to confusion about what exactly instructors expect of students. One instructor admitted being naive about Web resources and having no personal experience in locating information on the Web. She assumed that students would find the same quality of information on the Web as in other library materials. Based on the inadequate resources used by students, the other instructor concluded that the Web was a poor tool for her students to use. Students used the Web for research basically unchecked, largely because they had prior experience in using the Internet for electronic mail or chat rooms and felt they did not need assistance with research. One of the instructors, unaware of the students' reliance on their own judgment, believed that campus librarians were guiding students in their use of electronic and Web resources just as they did students in their use of traditional print sources.

\section{How Can Worries with the Web Be Reduced?}

Where do librarians go from here? Is there a way to reduce their worries with the Web? Two areas librarians need to address are how to deal with the instruc- tors' apparent lack of knowledge about the quality of Web resources and how to work with instructors to get information about Web resources across to students. Instructors must bear some responsibility for this. After all, they have more consistent contact with students and they more directly influence the values that students apply to the information sources they use (via classroom instruction, research requirements, and grades) than librarians do. But, as part of their long-standing role in academic institutions, librarians have a responsibility to make good sources of information available to students and faculty as well as to get the word out about both the possibilities and the perils of Web resources.

To help students distinguish between the good and the bad of Web resources, librarians need to continue to emphasize evaluative criteria. Because librarians do not control the resources available through the Web as they do with books and journals, they need to be able to guide students toward the worthwhile resources that can be found on the Web. This guidance has implications not only for bibliographic instruction, but also for Web design at the local level, for cataloging, and for staffing.

Although students have become increasingly sophisticated about using electronic resources, they are not yet sophisticated about searching them. College instructional programs should emphasize not only the application of evaluative criteria to their Web selections, but also to search strategies, including how to backtrack a Web page to locate information about authorship, biases, and credibility. While trying to change student perceptions, librarians probably also need to have a greater physical presence in the Information Commons or reference areas of the library. They need to be visible, available, and perhaps even more aggressive in offering assistance and suggesting Web sites (as well as print sources, which, after all, are sometimes more effective, easier to use, and easier to locate for many topics). As suggested by Scholz- 
Crane, students should be taught the components of Web documents in much the same ways-and for the same reasonsthat librarians formerly taught them the parts of catalog cards, books, and indexes.

Web pages posted by libraries need to be enticing, inviting, and easy to use. Students should find it easy to go to the pages prepared by librarians before seeking information through general search engines. Academic librarians should give considerable thought to Web page design, incorporating both the qualities they want students to know as well as the ease of use that less authoritative sites may have.

\section{Students need to learn where high- quality Web resources can be found by placing links in the same context as the library's other high-quality resource materials.}

Librarians should be moving steadily toward online library catalogs that include links to Web sites and electronic documents alongside other resources available in the campus library. Students need to learn where high-quality Web resources can be found by placing links in the same context as the library's other high-quality resource materials. The easier it is for students to locate "good" Web resources, the likelier they are to bypass the "bad" Web resources.

Because there is a gap between instructor expectations and student selections of Web resources, instructional programs should be twofold. Librarians should direct in-service training, one-on-one collaboration, publicity, Web page design, and other activities toward faculty. Librarians have had to learn to use the new technologies because that is the nature of their work, whereas many faculty members, some no longer actively involved in research in their fields, have not used Web resources extensively for research and are not yet proficient in using them. After librarians have begun working more closely to teach the faculty, they need to develop joint instructional programs with the faculty to teach the students. Although librarians typically find academic allies among the English faculty, they need to extend their affiliations so that information literacy or information competence is part of all curricula in all disciplines (or at least as many as can be reached).

At the very least, librarians need to encourage instructors to invite them to the classrooms and to bring their classes to the campus libraries. The unfettered availability of Web resources requires the use of critical thinking skills, in short supply among some students. Instructors should be convinced to spend some of their precious class time to help students hone their critical thinking skills and to use evaluative techniques to identify information sources. In fact, the identification and evaluation of information to solve problems should be a goal in and of itself, without necessarily being simply a step in the process of writing a research paper. Librarians themselves need to learn to foster critical thinking through their teaching. Additional research, comparing how students select print resources with how they select Web resources, might shed more light on student thinking and help librarians be more specific in their instructional programs.

As students use Web resources more frequently in different aspects of their lives, they are likely to remain confident in their abilities to locate acceptable sources of information without evaluating the sources they find, thinking they need no assistance from librarians or anyone else. Their unchecked and uninformed use of Web resources will likely continue. At the least, this would be a shame; at the most, it would be a disgrace. Concerted efforts by librarians and instructors can increase the odds that students will learn how to use Web resources effectively in all aspects of their lives. Librarians' worries with the Web may not be banished, but they certainly will be diminished. 


\section{Notes}

1. Evan Ira Farber, "Plus Ça Change ..., " Library Trends 44 (1995): 430-38.

2. David Rothenberg, "How the Web Destroys Student Research Papers," Education Digest 63 (Feb. 1998): 59-61.

3. Kari Boyd McBride and Ruth Dickstein, "The Web Demands Critical Thinking by Students," Chronicle of Higher Education (Mar. 20, 1998): B6.

4. Gloria J. Leckie, “Desperately Seeking Citations: Uncovering Faculty Assumptions about the Undergraduate Research Process," Journal of Academic Librarianship 22 (May 1996): 201-9.

5. Susan E. Hahn, "Let the User Beware," RSR: Reference Services Review 25 (1997): 7-13. Examples of these kinds of articles include: Lee Konrad and James Stemper, "Same Game, Different Name: Demystifying Internet Instruction," Research Strategies 14 (winter 1996): 4-21; Judith M. Pask and Carl E. Snow, "Undergraduate Instruction and the Internet," Library Trends 44 (fall 1995): 306-17; Kristin Kubly, "Guiding Students in Using the World Wide Web for Research," ED 430519 (1997), available online at: http://www.mtsu.edu/ itconf/proceed97/kubly.html; Edmund F. Santa Vicca et al, "Evaluating Internet Sources," Reference Librarian 41-42 (1994): 22573.

6. Julia K. Nims and Linda Rich, "How Successfully Do Users Search the Web?" College \& Research Libraries News 59 (Mar. 1998): 155-58.

7. Ann Scholz-Crane, "Evaluating the Future: A Preliminary Study of How Undergraduate Students Evaluate Web Sources," RSR: Reference Services Review 26 (1998): 53-60.

8. Anne F. Pierce, "Improving the Strategies High School Students Use to Conduct Research on the Internet by Teaching Essential Skills and Providing Practical Experience," ED 427756 (1998).

9. Mary Ann Gilette and Carol Videon, "Seeking Quality on the Internet: A Case Study of Composition Students' Works Cited," Teaching English in the Two-Year College 26 (Dec. 1, 1998): 189-94.

10. Examples of guides to the evaluation of Web resources abound. See the following as typical: Elizabeth E. Kirk, "Evaluating Information Found on the Internet," available online at http:/ /milton.mse.jhu.edu:8001/research/education/net.html; Hope N. Tillman, "Evaluating Quality on the Net," available online at: http://www.tiac.net/users/hope/findqual.html; Michael Engle, "Evaluating Web Sites: Criteria and Tools," available online at: http:// www.library.cornell.edu/okuref/webreview.html; Jim Kapoun, "Teaching Undergraduates Web Evaluation," available online at: http://www.ala.org/acrl/undwebev.html. 